\title{
Barriers and Strategies to Implement e-procurement in the State Pharmaceuticals Corporation (SPC) of Sri Lanka
}

\author{
Koggalage PD.
}

\begin{abstract}
Introduction: Public procurement not only delivers goods and services to public, but also ensures value for money. An efficient system is vital to accomplish core principles of public procurement: transparency; fairness; competitiveness; value for money; efficiency, etc. The State Pharmaceuticals Corporation of Sri Lanka (SPC) procures pharmaceuticals for state health sector through traditional procurement which has inefficiencies affecting patient care services. Therefore, introduction of e-procurement in SPC is pivotal.
\end{abstract}

Objective: To obtain the perspectives of staff of the SPC about barriers and strategies to implement e-procurement for pharmaceuticals.

Methods: A descriptive cross-sectional study was designed to obtain perspectives of staff in selected sections of SPC about barriers and strategies to implement e-procurement for pharmaceuticals. Data was collected by a survey using a self-administered questionnaire which mainly contained five-point Likert scale questions and analysed using SPSS software.

Results \& conclusion: The majority was dissatisfied with the existing system which is less efficient, costly and less user-friendly. The majority agreed that lack of political and top level commitment, lack of knowledge and skills of the staff, lack of IT experts and necessary infrastructure facilities as barriers for implementation of e-procurement. Political advocacy, training of top level managers and staff members, development of necessary infrastructure facilities and Public-Private Partnership initiatives were perceived as viable strategies.

Research implications: The study obtained perspectives of staff about barriers and strategies for e-procurement initiatives, which will support successful implementation as they are the implementers and the end-users.

Keywords: electronic procurement; barriers and strategies to implement e-procurement; State Pharmaceuticals Corporation of Sri Lanka.

\section{Introduction}

\subsection{Overview of Procurement}

Obtaining of goods, services or works by procuring entities by the most appropriate means, with public funds or funds from any other source whether local or foreign received by way of loans, grants, gifts, donations, contributions and similar receipts is known as 'Public Procurement' (1). Public procurement has core principles such as transparency, equity, fairness, competitiveness, accountability, value for money, economy and efficiency, integrity and non-discrimination (2).

A traditional public procurement process is characterised by manual events. Therefore, it is more time consuming, expensive and prone to errors. Also, there needs to be large number of human resources to manage the process (3). Moreover, a traditional system has too much attention on procedural compliance rather than on its performance. Hence, it sometimes acts as a bottleneck to efficient service delivery, with unnecessary delays (2). Therefore, traditional processes can be enhanced by the application of Information and Communication Technology (ICT) which is known as electronic government procurement (e-GP) (4). It can streamline all aspects of the procurement system by simplifying processes (5). Also, e-GP will provide access to a larger marketplace, minimize the opportunity for manipulations and corruption (2).

\subsection{The State Pharmaceuticals Corporation of Sri Lanka}

The State Pharmaceuticals Corporation of Sri Lanka (SPC) has been established with the objective of supplying pharmaceuticals and other medical consumables to all health institutions under the Ministry of Health, Sri Lanka (6). It acts as the central procurement arm for pharmaceuticals for the Ministry of Health. Its existing traditional, paper-based procurement process faces many challenges in fulfilling escalating demands of the country. Introduction of e-procurement methods will be a good solution to ensure the efficiency, effectiveness and transparency of processes. Therefore, it was vital to obtain perspectives of the staff engaging in procurement activities in SPC about barriers and strategies for implementation of e-procurement methods as they will be the implementers and end users of the system. 


\subsection{Objective}

To describe the perspectives of the staff engaging in procurement activities in the SPC on barriers and strategies to implement e-procurement system for pharmaceuticals.

\section{Methods}

\subsection{Study design and setting}

This descriptive cross-sectional study was conducted in the selected sections of the SPC during the fivemonth period from October 2018 to February 2019. The selected sections were Pharmaceutical, SurgicalAnnual, Surgical-Special, Laboratory and Technical Divisions considering their level of involvement in the procurement process and the feasibility.

\subsection{Study population}

All the staff members who had at least six (6) months of service in the selected divisions of the SPC, engaging in the procurement process at different stages were purposively selected as the study population. The total number was 70 .

\subsection{Collection of data}

Collection of data was done by the Principal Investigator (PI) using a structured pre-tested, self-administered questionnaire prepared in English medium. The study analysed selected socio-demographic characteristics of respondents, their perspectives on the existing procurement process and also, the barriers and strategies for implementation of e-procurement for pharmaceuticals. Variables were identified under each specific aspect and operationalized by including relevant questions in the questionnaire. The responses for majority of questions were in the 'Five Point Likert Scale'. eg. 1. Very Satisfied

2. Satisfied

3. "N" (Neither Satisfied nor Dissatisfied)

4. Dissatisfied

5. Very Dissatisfied.

An 'Information Sheet' and a 'Consent Form' were provided with the questionnaire.

\subsection{Analysis of data}

The analysis of data was carried out by the PI using the Statistical Package in Social Sciences (SPSS), Version 21.0 software. Results have been presented using frequency distributions.

\subsection{Administrative and ethical requirements}

Permission to conduct the study was obtained from the General Manager of the SPC.

Participation in this study was completely voluntary. Purpose and issues related to the study were explained to every participant using the Information Sheet and informed consent was obtained. Information gathered was kept confidential. Only the aggregated data was presented and published.

\section{Results}

Out of all the staff members under consideration $(n=70)$, 60 responded to the questionnaire with a response rate of $85.7 \%$.

\subsection{Socio-demographic characteristics of the} respondents

As depicted in Table I below, among the respondents, $41.7 \%$ and $38.3 \%$ were in age groups $19-30$ and $31-40$ years respectively. The majority was females (70\%). The large majority, $73.3 \%$ included Management Assistants at the operational level.

Table I - Frequency distribution of respondents by selected socio-demographic characteristics

\begin{tabular}{lcc}
\hline Characteristic & Frequency $\mathbf{( n = 6 0 )}$ & Percentage \\
\hline Age groups/ Years & & \\
$19-30$ & 25 & 41.7 \\
$31-40$ & 23 & 38.3 \\
$41-60$ & 12 & 20.0 \\
\hline Sex & & \\
Male & 18 & 30.0 \\
Female & 42 & 70.0 \\
\hline Designation & & \\
Deputy General Manager & 03 & 5.0 \\
Supervisor & 05 & 8.3 \\
Procurement Officer & 08 & 13.4 \\
Management Assistant & 44 & 73.3 \\
\hline
\end{tabular}




\subsection{Perspectives of respondents on the existing procurement system at SPC}

The perception of respondents about the average lead time is shown in Figure I below.

\section{Figure I - Perception of respondents about average time taken to receive goods from order date (lead time)}

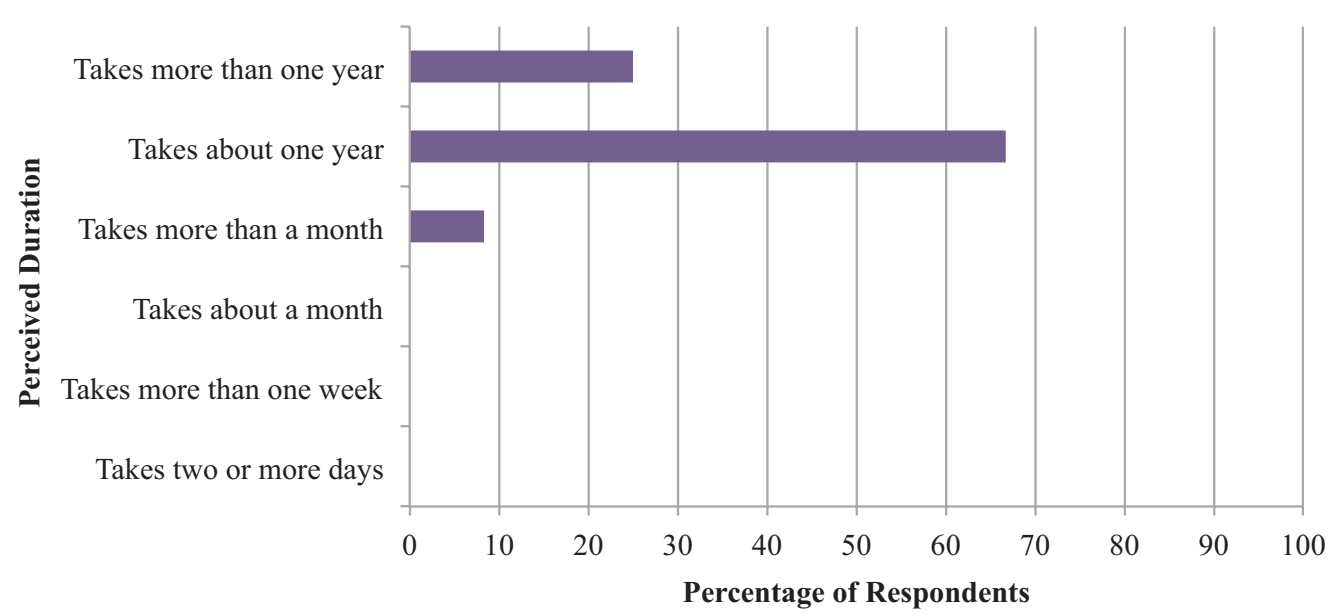

The large majority, $66.7 \%$ was of the view that the average time taken to receive goods (lead time) is about one year. The level of agreement of respondents with the existing procurement process is shown in Figure II.

\section{Figure II - The level of agreement of respondents with the following features of the existing procurement process in SPC}

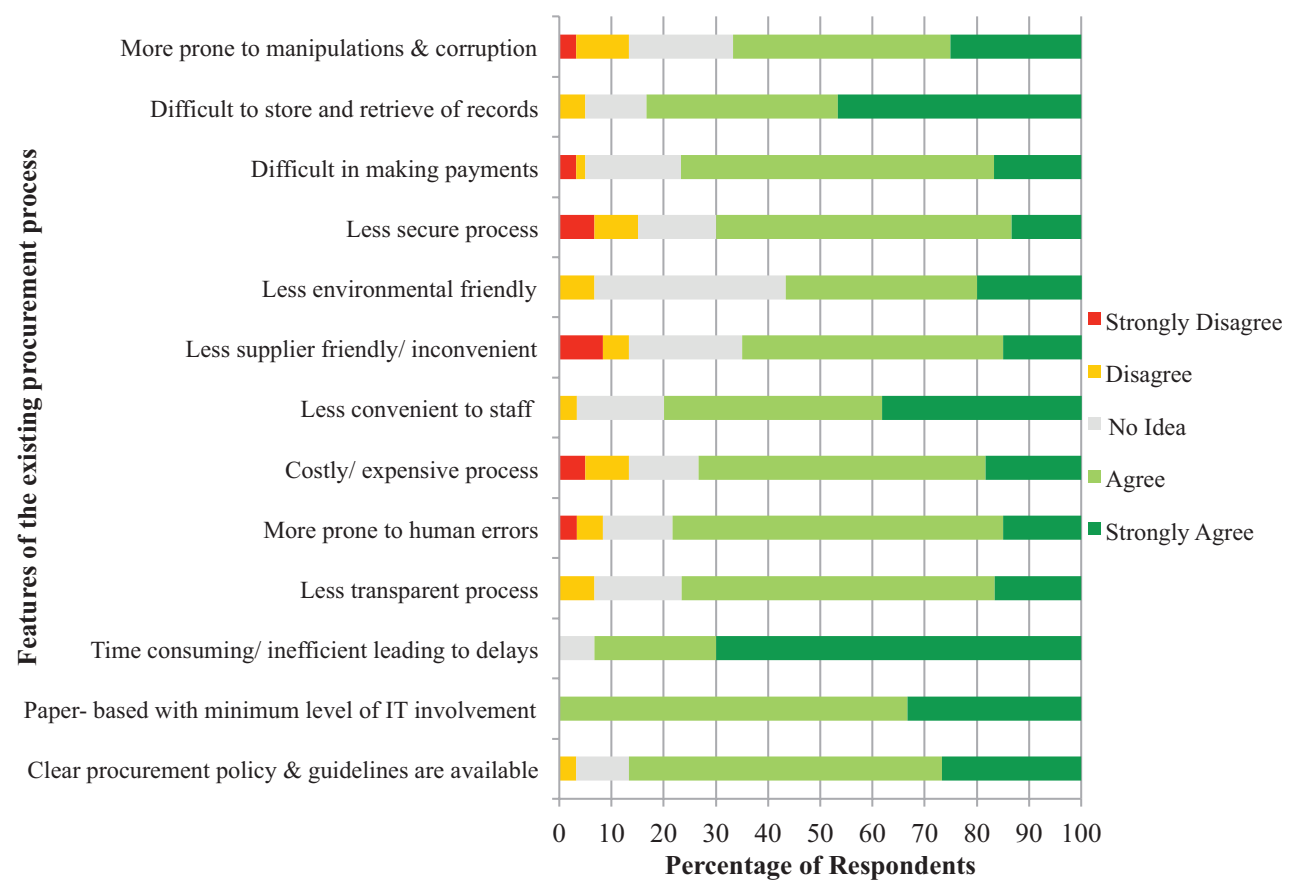

The majority, $60 \%$ agreed that clear procurement policies and guidelines are available at present while another $26.7 \%$ strongly agreed with that. The large majority either agreed $(66.7 \%)$ or strongly agreed $(33.3 \%)$ that the existing system is paper-based with minimal IT support. Seventy percent strongly agreed that the existing system is more time consuming and inefficient while $60 \%$ agreed that this is a less transparent and $63.3 \%$ agreed that it is more prone to human errors. The majority either agreed $(41.7 \%)$ or strongly agreed $(25 \%)$ that the existing procurement system is more prone to manipulations and corruptions. 
Table II shows respondents' overall level of satisfaction about the existing process of procurement at SPC.

Table II - Overall level of satisfaction of respondents about the existing procurement process in SPC

\begin{tabular}{|c|c|c|c|c|c|c|c|c|c|c|c|c|}
\hline \multicolumn{13}{|l|}{ Level of satisfaction } \\
\hline \multirow[t]{2}{*}{ Satisfaction } & \multicolumn{2}{|c|}{$\begin{array}{c}\text { Very } \\
\text { Dissatisfied }\end{array}$} & \multicolumn{2}{|c|}{ Dissatisfied } & \multicolumn{2}{|c|}{ No Idea } & \multicolumn{2}{|c|}{ Satisfied } & \multicolumn{2}{|c|}{$\begin{array}{c}\text { Very } \\
\text { Satisfied }\end{array}$} & \multicolumn{2}{|c|}{ Total } \\
\hline & No. & $\%$ & No. & $\%$ & No. & $\%$ & No. & $\%$ & No. & $\%$ & No. & $\%$ \\
\hline Overall level of satisfaction & 08 & 13.3 & 32 & 53.4 & 12 & 20.0 & 08 & 13.3 & 00 & 0.0 & 60 & 100.0 \\
\hline
\end{tabular}

It was evident that the majority of participants were either dissatisfied (53.4\%) or very dissatisfied (13.3\%) with the existing procurement process at the SPC.

\subsection{Perspectives of respondents on barriers to implement e-procurement in SPC}

Their level of agreement with the perceived barriers for implementing an e-procurement system in SPC is shown in Figure III.

Figure III - The level of agreement of respondents with the perceived barriers for implementing e-procurement in SPC

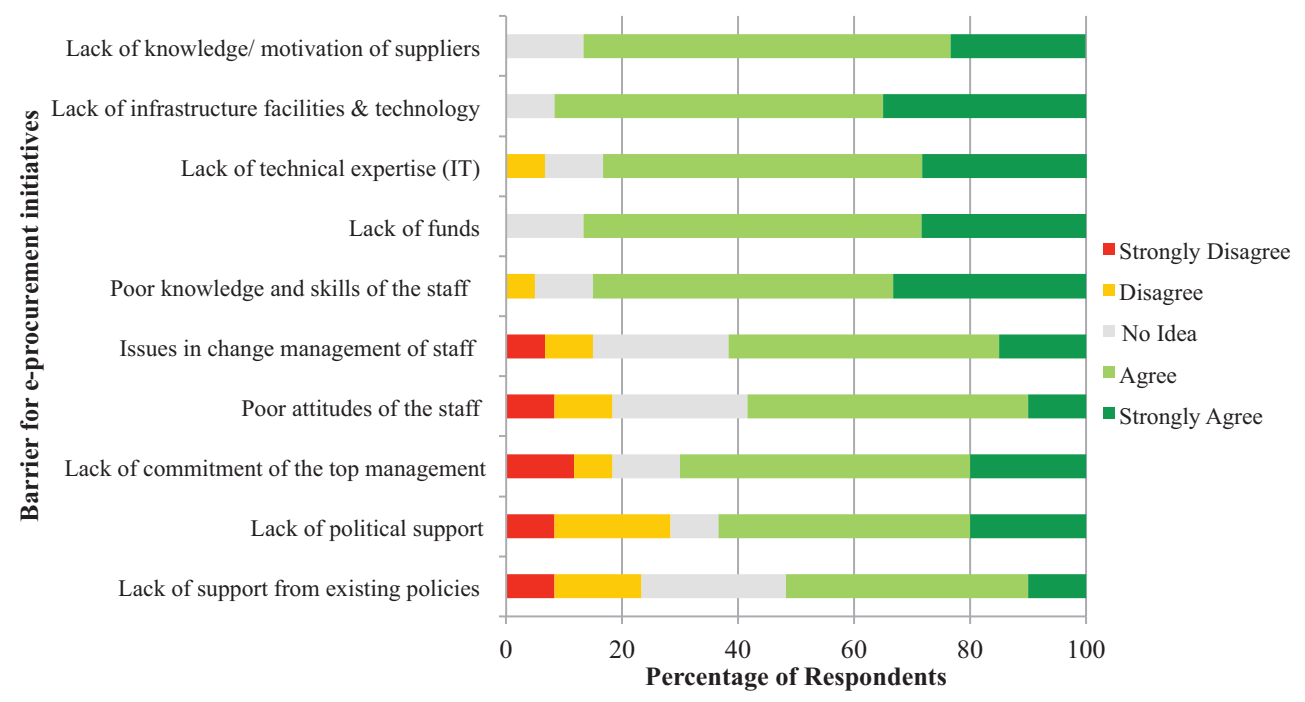

Most of the participants either agreed $(41.7 \%)$ or strongly agreed (10\%) that the existing policies and guidelines act as barriers in implementing e-procurement systems. About $61 \%$ either agreed or strongly agreed that there is lack of political support while $70 \%$ either agreed or strongly agreed that there is lack of commitment from the top management. The majority either agreed $(51.7 \%)$ or strongly agreed $(33.3 \%)$ that lack of knowledge and skills of the staff acts as a barrier. The majority, 56.7\% and 35\% agreed and strongly agreed respectively that lack of infrastructure facilities and technology in the institution as a barrier.

\subsection{Perspectives of respondents on strategies to implement e-procurement in SPC}

Their level of agreement with the following strategies to implement an effective e-procurement system in SPC is shown in Figure IV. 


\section{Figure IV - The level of agreement of respondents with the following strategies to implement an e-procurement system in SPC}

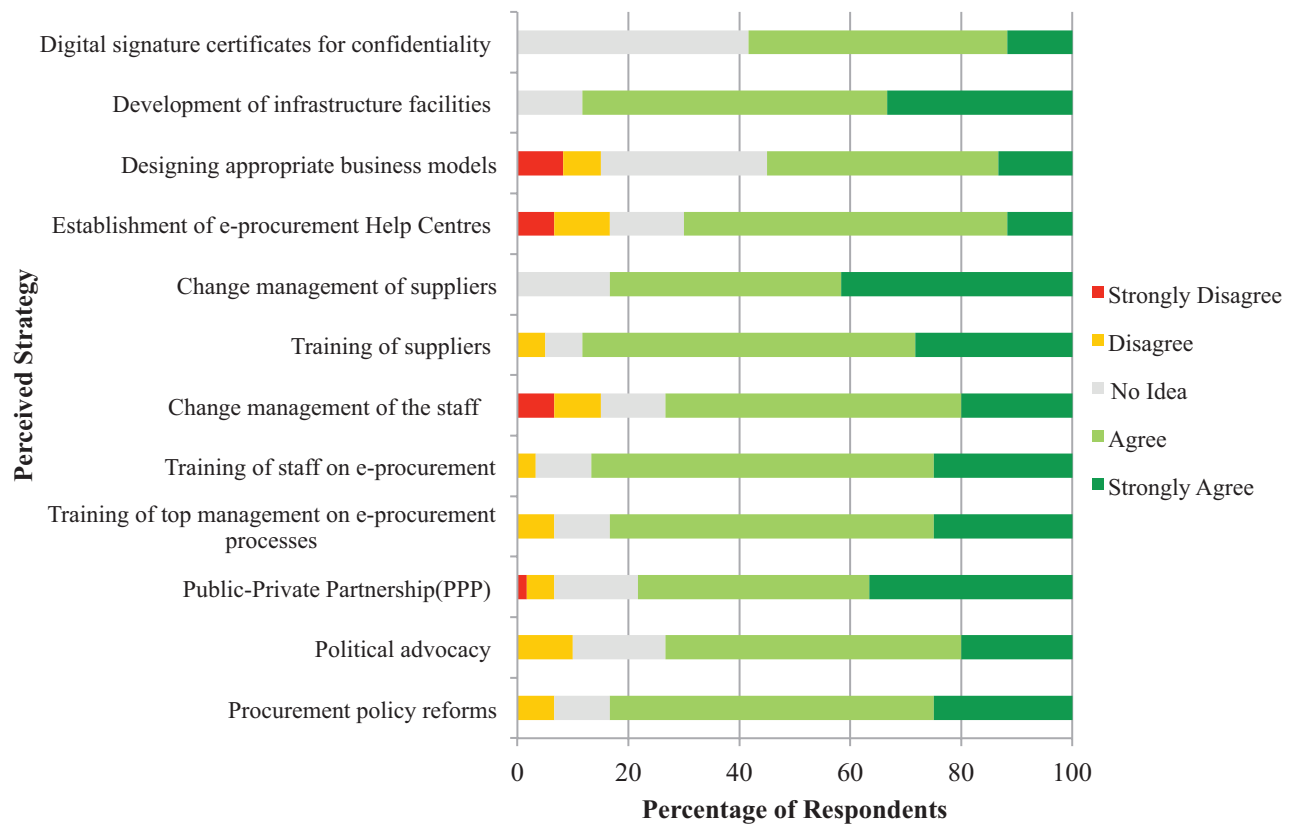

The majority either agreed $(58.3 \%)$ or strongly agreed $(25 \%)$ that there should be policy reforms in order to implement e-procurement systems. About $73 \%$ either agreed or strongly agreed that political advocacy is an important strategy. A large majority $(78.3 \%)$ either agreed or strongly agreed that PPP can be a viable strategy in this regard. About $83 \%$ either agreed or strongly agreed that the top management should be trained while it was $86 \%$ for training of the staff. About $88 \%$ either agreed or strongly agreed with the strategy to develop infrastructure facilities for e-procurement.

\section{Discussion}

Traditional public procurement gives too much attention to compliance on procedures rather than on its performance. Therefore, procurement has often become a barrier to efficient service delivery (2). In many countries, traditional procurement processes have considerable inefficiencies which adversely affect the achievement of value for money in the procurement of goods and services (7). Similarly, in Sri Lanka also, the supply of pharmaceuticals has been adversely affected due to delays in traditional procurement procedures. Hence, it is high-time to automate procurement process of the SPC. This study was designed aiming at describing the perspectives of the staff of the SPC about perceived barriers and strategies for implementation of e-procurement. Out of 70 relevant staff members, 60 responded (response rate $=85.7 \%$ ) to the selfadministered questionnaire with five-point Likert scale questions.
About the existing procurement system, the majority $(66.7 \%)$ mentioned that the average lead time is about one year while another $25 \%$ said it's more than one year. Mawenya (2008) has also identified this delay as one of the challenges (7). However, it is not only delays in the procurement process that leads to this considerable lead time, but also other reasons which need further analysis.

The large majority either agreed $(66.7 \%)$ or strongly agreed $(33.3 \%)$ that the existing system is a paperbased one with minimal IT support. As Claritum (2009) discussed, this type of traditional procurement process will consume more time mainly for managing the approvals, invoices and bills on paper which is more prone to errors and loss of paperwork (3). The majority of the present study strongly agreed that the existing system is more time consuming, inefficient, costly, more prone to errors and less transparent. Therefore, the majority was either dissatisfied $(53.4 \%)$ or very dissatisfied $(13.3 \%)$ with the existing procurement process at the SPC. All these findings are consistent with discussions of both Claritum (2019) and Komakech (2016) (2,3).

The majority agreed that the existing policies and guidelines, lack of political support, lack of commitment from the top level management, lack of IT experts, lack of necessary infrastructure facilities and technology and lack of knowledge and skills of the staff on e-procurement act as barriers. A similar study conducted in Kenya also revealed that the employees' poor level of e-procurement skills had affected implementation of e-procurement (8). 
The majority in this study either agreed or strongly agreed that there should be policy reforms, political advocacy and the commitment of top level management in order to implement e procurement successfully. Similarly, Clifford McCue (2012) also recommended that all the relevant stakeholders; policymakers, system designers, and procurement professionals must be involved at all stages of e-procurement implementation (9). Training the management and the staff, development of necessary infrastructure facilities and PPP initiatives were other important strategies for which the majority agreed.

\subsection{Limitations}

The study was limited to purposively selected Divisions of the SPC due to time constraints. Analysis was limited to calculation of percentages due to limited time.

\section{Conclusion and Recommendations}

This descriptive cross-sectional study was designed to describe the perception of staff members of the SPC towards implementation of an e-procurement system for pharmaceuticals.

The majority was dissatisfied with the existing traditional procurement process of the SPC and agreed that lack of political advocacy and top level commitment, poor knowledge and skills of staff and lack of necessary infrastructure facilities and expertise as barriers for implementation of e-procurement. Hence, political advocacy, top level commitment, training of staff and PPP initiatives were possible strategies agreed upon by respondents.

Therefore, the study recommended the following.

- Advocate political leaders and top level managers on the importance of implementing e-procurement in SPC.

- Establish PPP initiatives for funding for infrastructure developments, technology and also for expertise.

- Conduct in-service training programmes on e-procurement methods for staff.

\section{References}

1. National Procurement Agency. (2006). Procurement Guidelines 2006. Colombo: Department of Government Printing, Sri Lanka.

2. Komakech, R. A. (2016). Public Procurement in Developing Countries: Objectives, Principles and Required Professional Skills . Public Policy and Administration Research, pp. 20-29.
3. Claritum. (2019). The Challenges of Traditional Procurement Process. Retrieved from Claritum: http://www.claritum.com/challenges-traditionalprocurement-process/ (Accessed 23 November 2018)

4. The World Bank Group. (2019). e-procurement learning. Retrieved from The World Bank Group: https:/olc.worldbank.org/content/e-procurementlearning-self-paced (Accessed 15 December 2018)

5. Oxford College of Procurement and Supply. (2014). The Benefits of e-procurement. Retrieved from Oxford College of Procureement and Supply: https:// www.oxfordcollegeof procurementand supply. com/the-benefits-of-e-procurement/ (Accessed 22 October 2018)

6. SPC. (2015). About SPC. Retrieved from State Pharmaceuticals Corporation of Sri Lanka (SPC): http://www.spc.lk/about-spc.php (Accessed 15 October 2018)

7. Mawenya, A. (2008). Preventing corruption in Africa. Occassional Paper. Johannesburg: SAIIA.

8. McCue, A. V. (2012). E-Procurement: Myth or Reality. Journal of Public Procurement, pp. 221248.

9. Wilfred Nyagaka Mbeche, N. J. (2014). Employees' Level of E-Procurement Skills as a Challenge Facing the Implementation of Electronic Procurement System at Nakuru Water \& Sanitation Services Ltd, Nakuru, Kenya. International Journal of Science and Research (IJSR), pp. 499-502. 